\title{
Modeling Macroeconomic Variables Using Principal Component Analysis and Multiple Linear Regression: The Case of Ghana's Economy
}

\author{
Eyiah-bediako Francis $^{1}$, Bosson-amedenu Senyefia ${ }^{2,}$, Otoo Joseph $^{3}$ \\ ${ }^{1}$ Department of Statistics, University of Cape Coast, Cape Coast, Ghana \\ ${ }^{2}$ Department of Mathematics and ICT, Holy Child College of Education, Takoradi, Ghana \\ ${ }^{3}$ Department of Statistics and Actuarial Science, University of Ghana, Legon, Greater Accra, Ghana \\ Email address: \\ senyefia@yahoo.com (Bosson-amedenu S.) \\ ${ }^{*}$ Corresponding author
}

\section{To cite this article:}

Eyiah-bediako Francis, Bosson-amedenu Senyefia, Otoo Joseph. Modeling Macroeconomic Variables Using Principal Component Analysis and Multiple Linear Regression: The Case of Ghana's Economy. Journal of Business and Economic Development.

Vol. 5, No. 1, 2020, pp. 1-9. doi: 10.11648/j.jbed.20200501.11

Received: December 25, 2019; Accepted: January 4, 2020; Published: January 13, 2020

\begin{abstract}
The paper sought to model the relationship between GDP and 29 macroeconomic variables in Ghana using the Principal Component Analysis and multiple linear regression. Economic data with 583 data points were collected from January, 1990 through to May, 2018. The KMO statistics was 0.750 and the Bartlett's Test of sphericity statistic obtained for the data was 24807.231 of p-value 0.000 . The variables were found to be powerfully correlated with reference to the correlation matrix. Principal Component Analysis was performed to reduce the factors (using orthogonal varimax technique to produce uncorrelated factor structures to help allocate appropriately loadings to factors) to a minimum without compromising the variability of the original data. Seven factors were retained (explained $74 \%$ of the overall variation) after using multiple extraction approaches of Scree test, Kaiser Criterion and parallel analysis to avoid over- and under-extraction errors. Regression analysis was performed where component scores were used to develop a relationship with the uncorrelated components and GDP. The component 2 (Closed Economy without Government Activities) explicitly contained seven indicators consisting of consumer price index-Food, Consumer price index-Nonfood, Consumer Price index (overall), Monetary Policy Rate, 91-Days Treasury Bill, 182-Days Treasury Bill, crude oil, and Core Inflation (Adjusted for Energy and Utility). Component 2 was significant and positively related with GDP $(B=0.6, p<0.01)$. Again, Component 5 (Closed Economy with Government activities) explicitly contained two indicators such as Tax-Equivalent Rate on 28-Days Treasury Bill and Tax-Equivalent Rate on 56-DaysTreasury Bill. Component 5 had a positive and significant impact on GDP $(B=0.386$, $\mathrm{p}<0.01$ ). However, component 4 (monetary economy; $\mathrm{B}=-3.927, \mathrm{p}<0.01$ ), component $6(\mathrm{~B}=-0.577, \mathrm{p}<0.01$ ) and component $7(B=-0.256, p<0.01)$ were negatively related with GDP but were statistically significant. The R-squared value of 0.304 shows that the regression model explains about $30 \%$ of the variance. It was recommended for future researchers to consider increasing the number of macroeconomic variables to increase the predictive power of the model.
\end{abstract}

Keywords: Principal Component Analysis, Modeling, Macroeconimic Economic Variables, Ghana, Factor Analysis, Eigenvalues, Multiple Linear Regression

\section{Introduction}

Principal components analysis (PCA) has been extensively applied in diverse fields as a multivariate approach in reducing the dimension of data points so as to facilitate the interpretation and construction of predictive models [1].
Decomposition and dimensional reduction techniques such as Principal component analysis is recommended for a study that involves exploring multidimensional data [2].

Syed et al., (2013), [3] sought to measure the effects of macroeconomic variables on Gross Domestic Product (GDP) in Pakistan using principal component analysis and factor 
analysis. From their results, seventeen variables contributing to GDP were retained in three factors. These three factors derived by the method of PCA were the service factor, agriculture \& infrastructure factor, and the fishing \& mining factor. In the maximum likelihood method the factors we renamed as service factor, agriculture $\&$ infrastructure factor, and education factor.

Hussain et al. (2016), [4] also examined the impact of macroeconomic variables on GDP in Pakistan using multiple regression model. The study found a significant effect on inflation rate, interest rate, and exchange rate on GDP.

A study by Purnamasari et al. (2019), [5] determined the factors capable of affecting learning motivation of students at Yogyakarta State University Postgraduate Program. By the method of Factor analysis, six factors were identified to affect student motivation. These factors were diligence, discipline, discipline and learning frequency, motivation, independence, time management.

A study by Adongo et al. (2018), [6] used PCA to determine the extent of redundant information from correlation matrix. Varimax rotation was applied. Three factors were retained by scree test. The first factors had 6 indicator loadings, the second had one indicator loading, and the third factor had one indicator loading between the nine macroeconomic indicators. They established that PCA method was more robust in comparison with maximum likelihood estimate MLE method. However, the researchers failed to consider varied extraction approaches prior to making decisions on the number of components to retain. This is noteworthy as since the Scree test is known to be highly subjective.

Razak et al. (2015), [7] applied PCA to socioeconomic variables in Asia and found a strong significant and positive correlation between life expectancy at birth and health expenditures, gross national income, good governance, and a healthy life. The study however did not consider the parallel analysis in decision making with regards to the number of components to retain.

Twenefour et al. (2015), [8] in their study sought to identify a yardstick for measuring student performance in a public school in Ghana using PCA. The researchers retained three components using scree test and Kaiser Criterion. The parallel analysis method which has been found to be the most robust method was not incorporated.

The ability of researchers to correctly determine the number of components to retain in PCA has been a major problem confronting researchers. Errors arising from such problems may lead to over-extraction or under-extraction. Field (2005), [9] suggested that if the sample size is more than 250 and the average communality is above 0.6 then one can retain all factors having Eigen values beyond 1 (Kaiser's criterion). He further suggested for Scree Plot to be used for sample size of at least 300. A study by Scott et al. (1995), [10] reviewed articles that applied PCA (by comparing the three methods such as scree plot, Kaiser Criterion and parallel analysis) from 1987-1993 found that parallel analysis was the most robust method in deciding on the number of components to retain. Williams (2012), [11] suggested that multiple extraction techniques should be explored before making decisions to retain prospective components.

\section{Method}

The study examined 30 economic variables (with samples obtained from 583 data points) in Ghana. Data was obtained from the Bank of Ghana (annual reports) panning the years from 1990 through to May of 2018. The analytical methods of PCA and regression analysis were employed.

\subsection{Construction of Principal Components}

For a random vector, $X$, with domain $\mathfrak{R}^{m}$, will have a mean and covariance matrix of $\mu_{X}$ and $\Sigma_{X}$, respectively. $\lambda_{1}>\lambda_{2}>\cdots>\lambda_{m}>0$ for an array of eigenvalues of $\Sigma_{X}$, so that the $i$-th eigenvalue of $\Sigma_{X}$ represents the largest $i$-th eigenvalue. Suppose a vector $\alpha_{i}$ denotes the $i$-th eigenvector of $\Sigma_{X}$ corresponding to the $i$-th eigenvalue of $\Sigma_{X}$. We wish to derive principal components (PCs) form by considering the maximization of $\operatorname{var}\left[\alpha_{1}^{T} X\right]=\alpha_{1}^{T} \sum_{X} \alpha_{1}$, with respect to $\alpha_{1}^{T} \alpha_{1}=1$ (a typical optimization problem). The Lagrange multiplier approach is then applied to solve the problem.

To that end,

$$
\begin{gathered}
L\left(\alpha_{1}, \varphi_{1}\right)=\alpha_{1}^{T} \sum_{X} \alpha_{1}+\varphi_{1}\left(\alpha_{1}^{T} \alpha_{1}-1\right) \\
\frac{\partial L}{\partial \alpha_{1}}=2 \sum_{X} \alpha_{1}+2 \varphi_{1} \alpha_{1}=0 \Rightarrow \sum_{X} \alpha_{1}=-\varphi_{1} \alpha_{1} \Rightarrow \\
\operatorname{var}\left[\alpha_{1}^{T} X\right]=-\varphi_{1} \alpha_{1}^{T} \alpha_{1}=-\varphi_{1}
\end{gathered}
$$

Since $-\varphi_{1}$ represent the eigenvalue of $\Sigma_{X}$, with $\alpha_{1}$ denoting the respective normalized eigenvector, $\operatorname{var}\left[\alpha_{1}^{T} X\right]$ is maximized when $\alpha_{1}$ chosen as the initial eigenvector of $\Sigma_{X}$. To this end, $z_{1}=\alpha_{1}^{T} X$ is reffered to as the first PC of $X$, with $\alpha_{1}$ representing the vector of coefficients for $z_{1}$, where $\operatorname{var}\left(z_{1}\right)=\lambda_{1}$.

To get the second PC, $z_{2}=\alpha_{2}^{T} X$, we shall maximize $\operatorname{var}\left[\alpha_{2}^{T} X\right]=\alpha_{2}^{T} \Sigma_{X} \alpha_{2}$ on condition that ${ }_{2}$ is not correlated with ${ }^{z_{1}}$. But $\operatorname{cov}\left(\alpha_{1}^{T} X, \alpha_{2}^{T} X\right)=0 \Rightarrow \alpha_{1}^{T} \sum_{X} \alpha_{2}=0 \Rightarrow$ $\alpha_{1}^{T} \alpha_{2}=0$, which we will solve by maximizing $\alpha_{2}^{T} \Sigma_{X} \alpha_{2}$, on condition that $\alpha_{1}^{T} \alpha_{2}=0$, and $\alpha_{2}^{T} \alpha_{2}=1$. We again make use of the Lagrange multiplier approach.

To that end,

$$
L\left(\alpha_{2}, \varphi_{1}, \varphi_{2}\right)=\alpha_{2}^{T} \Sigma_{X} \alpha_{2}+\varphi_{1} \alpha_{1}^{T} \alpha_{2}+\varphi_{2}\left(\alpha_{2}^{T} \alpha_{2}-1\right)
$$




$$
\begin{gathered}
\frac{\partial L}{\partial \alpha_{2}}=2 \sum_{X} \alpha_{2}+\varphi_{1} \alpha_{1}+2 \varphi_{2} \alpha_{2}=0 \\
\Rightarrow \alpha_{1}^{T}\left(2 \sum_{X} \alpha_{2}+\varphi_{1} \alpha_{1}+2 \varphi_{2} \alpha_{2}\right)=0 \Rightarrow \varphi_{1}=0 \\
\Rightarrow \sum_{X} \alpha_{2}=-\varphi_{2} \alpha_{2} \Rightarrow \alpha_{2}^{T} \sum_{X} \alpha_{2}=-\varphi_{2} .
\end{gathered}
$$

As $-\varphi_{2}$ is the eigenvalue of $\sum_{X}$, where $\alpha_{2}$ is the respective normalized eigenvector, we are able to maximize $\operatorname{var}\left[\alpha_{2}^{T} X\right]$ when we select $\alpha_{2}$ as the second eigenvector of $\Sigma_{X}$. As a result, $z_{2}=\alpha_{2}^{T} X$ becomes the second PC of $X$, where $\alpha_{2}$ represents the vector of coefficients for $z_{2}$, and $\operatorname{var}\left(z_{2}\right)=\lambda_{2}$. Per the above results, we can deduce that the $i$ -th PC $z_{i}=\alpha_{i}^{T} X$ is constructed $\alpha_{i}$ is chosen as the $i$-th eigenvector of $\sum_{X}$, which will then have the variance $\lambda_{i}$. We can conclude by the above results that PCA are the only set of linear functions of original data that are uncorrelated and have orthogonal vectors of coefficients. PCA relies on either covariance matrix or the correlation matrix. The linear combination weights directly originate from combination eigenvectors of correlation matrix or covariance matrix.

Recall that for $\mathrm{m}$ variables, the $m \times m$ covariance or correlation matrix will contain the following sets:

$$
\begin{gathered}
\mathrm{m} \text { eigenvalues }-\left\{\mathrm{l}_{1}, \mathrm{l}_{2}, \ldots, \mathrm{l}_{\mathrm{p}}\right\} \\
\mathrm{m} \text { eigenvectors }-\left\{\mathrm{e}_{1}, \mathrm{e}_{2}, \ldots, \mathrm{e}_{\mathrm{p}}\right\} .
\end{gathered}
$$

E ach principal component (PC) formed when we considering the values of the elements of the eigenvalues as the weights of the linear combination $[6,12]$.

Assuming that the $\mathrm{k}$-th eigenvector $\mathrm{e}_{\mathrm{k}}=\left(\mathrm{e}_{1 \mathrm{k}}, \mathrm{e}_{2 \mathrm{k}}, \ldots, \mathrm{e}_{\mathrm{pk}}\right)$, then the PCs $\mathrm{Y}_{1}, \ldots$, are produced by

$$
\mathrm{Y}_{1}=\mathrm{e}_{11} \mathrm{X}_{1}+\mathrm{e}_{21} \mathrm{X}_{2}+\ldots+\mathrm{e}_{\mathrm{m} 1} \mathrm{X}_{m}
$$

$$
\begin{aligned}
& \mathrm{Y}_{2}=\mathrm{e}_{12} \mathrm{X}_{1}+\mathrm{e}_{22} \mathrm{X}_{2}+\ldots+\mathrm{e}_{\mathrm{m} 2} \mathrm{X}_{m} \cdots \\
& \mathrm{Y}_{m}=\mathrm{e}_{1 \mathrm{~m}} \mathrm{X}_{1}+\mathrm{e}_{2 \mathrm{~m}} \mathrm{X}_{2}+\ldots+\mathrm{e}_{m m} \mathrm{X}_{m}
\end{aligned}
$$

\subsection{Multiple Linear Regressions}

The data $\left(Y_{1}, z_{11}, z_{12}, \ldots, z_{1 r}\right),\left(Y_{2}, z_{21}, z_{22}, \ldots, z_{2 r}\right), \ldots,\left(Y_{n}, z_{n 1}, z_{n 2}, \ldots, z_{n r}\right)$ will have the following multiple linear regression model:

$$
Y_{i}=\beta_{0}+\beta_{1} z_{i 1}+\beta_{2} z_{i 2}+\cdots+\beta_{r} z_{i r}+\varepsilon_{i}, i=1, \ldots, n,
$$

The terms satisfy the following properties:

$$
\text { 1. } E\left(\varepsilon_{i}\right)=0 ; \quad 2 \cdot \operatorname{Var}\left(\varepsilon_{i}\right)=\sigma^{2} ; \quad 3 \cdot \operatorname{Cov}\left(\varepsilon_{i}, \varepsilon_{j}\right)=0, i \neq j
$$

The matrix form of the above data is:

$$
Y=\left[\begin{array}{c}
Y_{1} \\
Y_{2} \\
\vdots \\
Y_{n}
\end{array}\right]=\left[\begin{array}{c}
\beta_{0}+\beta_{1} z_{11}+\cdots+\beta_{r} z_{1 r}+\varepsilon_{1} \\
\beta_{0}+\beta_{1} z_{21}+\cdots+\beta_{r} z_{2 r}+\varepsilon_{2} \\
\vdots \\
\beta_{0}+\beta_{1} z_{n 1}+\cdots+\beta_{r} z_{n r}+\varepsilon_{n}
\end{array}\right]=\left[\begin{array}{c}
\beta_{0}+\beta_{1} z_{11}+\cdots+\beta_{r} z_{1 r} \\
\beta_{0}+\beta_{1} z_{21}+\cdots+\beta_{r} z_{2 r} \\
\vdots \\
\beta_{0}+\beta_{1} z_{n 1}+\cdots+\beta_{r} z_{n r}
\end{array}\right]+\left[\begin{array}{c}
\varepsilon_{1} \\
\varepsilon_{2} \\
\vdots \\
\varepsilon_{n}
\end{array}\right]
$$

Or

$$
\left[\begin{array}{cccc}
1 & z_{11} & \cdots & z_{1 r} \\
1 & z_{21} & \cdots & z_{2 r} \\
\vdots & \vdots & \ddots & \vdots \\
1 & z_{n 1} & \cdots & z_{n r}
\end{array}\right]\left[\begin{array}{c}
\beta_{0} \\
\beta_{1} \\
\vdots \\
\beta_{r}
\end{array}\right]+\left[\begin{array}{c}
\varepsilon_{1} \\
\varepsilon_{2} \\
\vdots \\
\varepsilon_{n}
\end{array}\right]=Z \beta+\varepsilon
$$

Where;

$$
Y=\left[\begin{array}{c}
Y_{1} \\
Y_{2} \\
\vdots \\
Y_{n}
\end{array}\right], Z=\left[\begin{array}{cccc}
1 & z_{11} & \cdots & z_{1 r} \\
1 & z_{21} & \cdots & z_{2 r} \\
\vdots & \vdots & \ddots & \vdots \\
1 & z_{n 1} & \cdots & z_{n r}
\end{array}\right], \varepsilon=\left[\begin{array}{c}
\varepsilon_{1} \\
\varepsilon_{2} \\
\vdots \\
\varepsilon_{n}
\end{array}\right], \beta=\left[\begin{array}{c}
\beta_{0} \\
\beta_{2} \\
\vdots \\
\beta_{r}
\end{array}\right] .
$$

The error terms are;

Table 1. Interpretation of the KMO as characterised by Kaiser, Meyer, and Olkin.

\begin{tabular}{ll}
\hline KMO Value & Degree of Common Variance \\
\hline 0.90 to 1.00 & Marvelous \\
0.80 to 0.89 & Meritorious \\
0.70 to 0.79 & Middling \\
0.60 to 0.69 & Mediocre \\
0.50 to 0.59 & Miserable \\
0.00 to 0.49 & Not Appropriate for Factor Analysis \\
\hline
\end{tabular}

(Schwarz, 2011).

\section{Results}

William (2010), [11] suggested that the sample size of at least 300 and the sample-variable ratio of 10: 1 are adequate for factor analysis. The sample size for this study was made up of 583 data points from 30 economic variables in Ghana. 
Table 2. Truncated Correlation Matrix.

\begin{tabular}{|c|c|c|c|c|c|c|c|c|c|c|c|c|c|c|}
\hline & & CPIF & CPINF & CPIO & INFF & INFNF & INFYAV & INTYOY & M1 & M2 & M2PLUS & S MPR & TotDep & TotCred \\
\hline \multirow{27}{*}{ Correlation } & CPIF & 1.000 & .971 & .929 & -.444 & -.428 & -.480 & -.462 & .361 & .372 & .363 & -.733 & -.003 & .098 \\
\hline & CPINF & .971 & 1.000 & .935 & -.461 & -.422 & -.493 & -.464 & .481 & .490 & .482 & -.710 & .003 & .086 \\
\hline & CPIO & .929 & .935 & 1.000 & -.433 & -.402 & -.463 & -.440 & .417 & .426 & .417 & -.674 & -.013 & .085 \\
\hline & INFF & -.444 & -.461 & -.433 & 1.000 & .790 & .747 & .930 & -.375 & -.377 & -.373 & .576 & .123 & -.102 \\
\hline & INFNF & -.428 & -.422 & -.402 & .790 & 1.000 & .800 & .957 & -.227 & -.229 & -.224 & .604 & .046 & -.040 \\
\hline & INFYAV & -.480 & -.493 & -.463 & .747 & .800 & 1.000 & .837 & -.392 & -.393 & -.390 & .711 & .068 & -.037 \\
\hline & INFYOY & -.462 & -.464 & -.440 & .930 & .957 & .837 & 1.000 & -.297 & -.299 & -.294 & .645 & .095 & -.068 \\
\hline & M2 & .372 & .490 & .426 & -.377 & -.229 & -.393 & -.299 & .997 & 1.000 & .999 & -.324 & .164 & .034 \\
\hline & M2PLUS & .363 & .482 & .417 & -.373 & -.224 & -.390 & -.294 & .997 & .999 & 1.000 & -.318 & .168 & .033 \\
\hline & MPR & -.733 & -.710 & -.674 & .576 & .604 & .711 & .645 & -.323 & -.324 & -.318 & 1.000 & .145 & -.003 \\
\hline & TotDep & -.003 & .003 & -.013 & .123 & .046 & .068 & .095 & .161 & .164 & .168 & .145 & 1.000 & .084 \\
\hline & TotCred & .098 & .086 & .085 & -.102 & -.040 & -.037 & -.068 & .035 & .034 & .033 & -.003 & .084 & 1.000 \\
\hline & TBR91day & -.294 & -.302 & -.288 & .191 & .247 & .267 & .238 & -.149 & -.149 & -.147 & .433 & -.184 & .021 \\
\hline & n TBR182DAY & -.039 & -.017 & -.029 & -.283 & -.331 & -.273 & -.320 & .149 & .149 & .153 & -.013 & -.050 & .050 \\
\hline & STD & .027 & .041 & .031 & -.135 & -.059 & -.069 & -.099 & .253 & .245 & .250 & -.059 & .046 & .072 \\
\hline & RMPGRATE & -.005 & .000 & -.006 & .045 & .009 & .056 & .026 & -.018 & -.018 & -.020 & .005 & .027 & -.185 \\
\hline & $\mathrm{RM}$ & -.227 & -.174 & -.182 & .325 & .238 & .176 & .293 & .065 & .065 & .068 & .183 & .538 & .057 \\
\hline & QM & -.144 & -.132 & -.128 & .412 & .330 & .275 & .384 & -.059 & -.058 & -.058 & .214 & .558 & .067 \\
\hline & PSCREDIT & -.169 & -.127 & -.112 & .217 & .212 & .287 & .239 & -.030 & -.036 & -.027 & .374 & .108 & -.071 \\
\hline & PETROLEUM & .619 & .529 & .503 & -.209 & -.262 & -.280 & -.259 & -.060 & -.050 & -.057 & -.569 & .006 & .040 \\
\hline & CIC & -.231 & -.180 & -.187 & .308 & .208 & .149 & .267 & .077 & .076 & .079 & .178 & .517 & .066 \\
\hline & BNCG & -.228 & -.212 & -.205 & .319 & .249 & .198 & .292 & -.123 & -.122 & -.121 & .201 & .516 & .051 \\
\hline & BCROIL & .235 & .210 & .221 & -.151 & -.011 & -.044 & -.083 & .099 & .094 & .093 & -.072 & .042 & .153 \\
\hline & DDR28 & -.013 & -.017 & -.016 & -.018 & -.017 & .025 & -.017 & -.016 & -.017 & -.017 & .033 & -.011 & .028 \\
\hline & DIREq28 & .115 & .149 & .135 & -.207 & -.040 & -.117 & -.117 & .233 & .235 & .235 & .036 & .341 & .161 \\
\hline & DIREQ56 & .154 & .185 & .170 & -.221 & -.036 & -.108 & -.121 & .255 & .256 & .257 & -.009 & .386 & .174 \\
\hline & CIAER & -.316 & -.256 & -.246 & .076 & .105 & .124 & .108 & .147 & .142 & .146 & .396 & -.357 & -.065 \\
\hline \multirow{27}{*}{$\begin{array}{l}\text { Sig. (1- } \\
\text { tailed) }\end{array}$} & CPIF & & .000 & .000 & .000 & .000 & .000 & .000 & .000 & .000 & .000 & .000 & .474 & .009 \\
\hline & CPINF & .000 & & .000 & .000 & .000 & .000 & .000 & .000 & .000 & .000 & .000 & .473 & .020 \\
\hline & NFNF & .000 & .000 & .000 & .000 & & .000 & .000 & .000 & .000 & .000 & .000 & .133 & .165 \\
\hline & NFYAV & .000 & .000 & .000 & .000 & .000 & & .000 & .000 & .000 & .000 & .000 & .050 & .184 \\
\hline & NTYOY & .000 & .000 & .000 & .000 & .000 & .000 & & .000 & .000 & .000 & .000 & .011 & .050 \\
\hline & M1 & .000 & .000 & .000 & .000 & .000 & .000 & .000 & & .000 & .000 & .000 & .000 & .202 \\
\hline & M2 & .000 & .000 & .000 & .000 & .000 & .000 & .000 & .000 & & .000 & .000 & .000 & .204 \\
\hline & M2PLUS & .000 & .000 & .000 & .000 & .000 & .000 & .000 & .000 & .000 & & .000 & .000 & .210 \\
\hline & MPR & .000 & .000 & .000 & .000 & .000 & .000 & .000 & .000 & .000 & .000 & & .000 & .472 \\
\hline & TotDep & .474 & .473 & .373 & .002 & .133 & .050 & .011 & .000 & .000 & .000 & .000 & & \multirow[t]{2}{*}{.021} \\
\hline & TotCred & .009 & .020 & .020 & .007 & .165 & .184 & .050 & .202 & .204 & .210 & .472 & .021 & \\
\hline & ГBR91day & .000 & .000 & .000 & .000 & .000 & .000 & .000 & .000 & .000 & .000 & .000 & .000 & .305 \\
\hline & TBR182DAY & .173 & .341 & .242 & .000 & .000 & .000 & .000 & .000 & .000 & .000 & .373 & .114 & .116 \\
\hline & TBRIYEAR & .055 & .069 & .077 & .323 & .475 & .317 & .399 & .182 & .182 & .184 & .229 & .073 & .211 \\
\hline & STD & .257 & .162 & .231 & .001 & .077 & .048 & .009 & .000 & .000 & .000 & .079 & .136 & .041 \\
\hline & RMPGRATE & .457 & .499 & .445 & .138 & .416 & .090 & .265 & .330 & .335 & .318 & .450 & .261 & .000 \\
\hline & $\mathrm{RM}$ & .000 & .000 & .000 & .000 & .000 & .000 & .000 & .059 & .060 & .050 & .000 & .000 & .085 \\
\hline & QM & .000 & .001 & .001 & .000 & .000 & .000 & .000 & .077 & .080 & .082 & .000 & .000 & .052 \\
\hline & PSCREDIT & .000 & .001 & .004 & .000 & .000 & .000 & .000 & .238 & .195 & .256 & .000 & .005 & .044 \\
\hline & PETROLEUM & .000 & .000 & .000 & .000 & .000 & .000 & .000 & .075 & .116 & .083 & .000 & .445 & .168 \\
\hline & CIC & .000 & .000 & .000 & .000 & .000 & .000 & .000 & .031 & .034 & .028 & .000 & .000 & .056 \\
\hline & $\mathrm{BNCG}$ & .000 & .000 & .000 & .000 & .000 & .000 & .000 & .002 & .002 & .002 & .000 & .000 & .108 \\
\hline & BCROIL & .000 & .000 & .000 & .000 & .397 & .147 & .023 & .009 & .012 & .012 & .043 & .157 & .000 \\
\hline & DDR28 & .380 & .337 & .354 & .335 & .345 & .273 & .340 & .347 & .341 & .344 & .211 & .399 & .252 \\
\hline & DIREq28 & .003 & .000 & .001 & .000 & .165 & .002 & .002 & .000 & .000 & .000 & .191 & .000 & .000 \\
\hline & DIREQ56 & .000 & .000 & .000 & .000 & .190 & .005 & .002 & .000 & .000 & .000 & .411 & .000 & .000 \\
\hline & CIAER & .000 & .000 & .000 & .034 & .006 & .001 & .005 & .000 & .000 & .000 & .000 & .000 & .059 \\
\hline
\end{tabular}

Relationship patterns were examined by critical analysis of the respective Pearson correlation coefficient (from the correlation matrix) between all pairs of the economic variables as well as their one-tailed significance of the coefficients. Multicollineality was a problem since the determinant of $1.119 \times 10^{-19}$ was smaller in value than the necessary value of 0.00001 . Therefore PCA application to the data will produce uncorrelated output which will deal with the issue of some economic variables being highly 
correlated with each other. A critical look at the correlation matrix (truncated) shows some highly correlated variables such as CPIF and CPIFN, M1 and M2 among others. There was a case of singularity of the data since numerous data sets yielded significance above 0.5 whilst a number of the correlation coefficients were more than 0.9 .

Table 3. Kaiser-Meyer-Olkin (KMO) Measure of Sampling Adequacy/Bartlett's Test of Sphericity.

\begin{tabular}{lll}
\hline \multicolumn{2}{l}{ KMO and Bartlett's Test } & \\
\hline \multicolumn{3}{l}{ Kaiser-Meyer-Olkin Measure of Sampling Adequacy. } \\
& Approx. Chi-Square & .750 \\
\multirow{2}{*}{ Bartlett's Test of Sphericity } & df & 24807.231 \\
& Sig. & 406 \\
& .000 \\
\hline
\end{tabular}

Null Hypothesis: The inter-correlation matrix of the variables is not different from an identity matrix.

Alternate Hypothesis: The inter-correlation matrix of the variables is different from an identity matrix.

Test Results

$\chi^{2}=24807.231 ; \mathrm{df}=406 ; \mathrm{p}<0.0001$

Statistical Decision

The inter-correlation matrix of the variables is significantly different from an identity matrix. In other words, the sample inter-correlation matrix did not come from a population in which the inter-correlation matrix is an identity matrix. The KMO Statistic was 0.750 . The degree of common variance among the ten variables is Middling.

In factor analysis, the factors extracted will account for a substantial amount of variance.

Factor analysis is recommended for analysis when the
Bartlett's test of sphericity is statistically significant $(\leq 0.05)$, and the KMO statistic exceeds 0.6 [14]. Kaiser-Meyer-Olkin Measure of Sampling Adequacy values which are greater than 0.7 by rule of thumb approach is considered a good indication that PCA will be useful for the variables under study (Williams, 2010). The KMO statistics of 0.750 is an indication of the appropriateness of the correlation matrix for component analysis. The Bartlett's test of Sphericity tests the difference between the correlation matrix for variables and the identity matrix. Bartlett's Test of Sphericity obtained for the data was 24807.231 and p-value was 0.000; an indication of a significant difference which makes it inferable that our correlation matrix for our measured variables is significantly different from an identity matrix which is consistent with the assumption that the matrix should be treated as factorable. This shows that the Bartlett's test of sphericity is highly sufficient for the data under study.

Table 4. The eigenvalues greater than one of the correlation matrix.

\begin{tabular}{llll}
\hline Eigenvalue & $\begin{array}{l}\text { Total variance } \\
(\%)\end{array}$ & $\begin{array}{l}\text { Cumulative } \\
\text { Eigenvalue }\end{array}$ & $\begin{array}{l}\text { Cumulative } \\
(\%)\end{array}$ \\
\hline 7.353 & 25.356 & 7.353 & 25.356 \\
4.629 & 15.961 & 11.982 & 41.317 \\
2.963 & 10.216 & 14.945 & 51.533 \\
2.159 & 7.445 & 17.104 & 58.979 \\
1.859 & 6.411 & 18.963 & 58.979 \\
1.4 & 4.827 & 20.363 & 65.389 \\
1.211 & 3.852 & 21.574 & 70.216 \\
1.117 & 4.176 & 22.691 & 74.329 \\
\hline
\end{tabular}

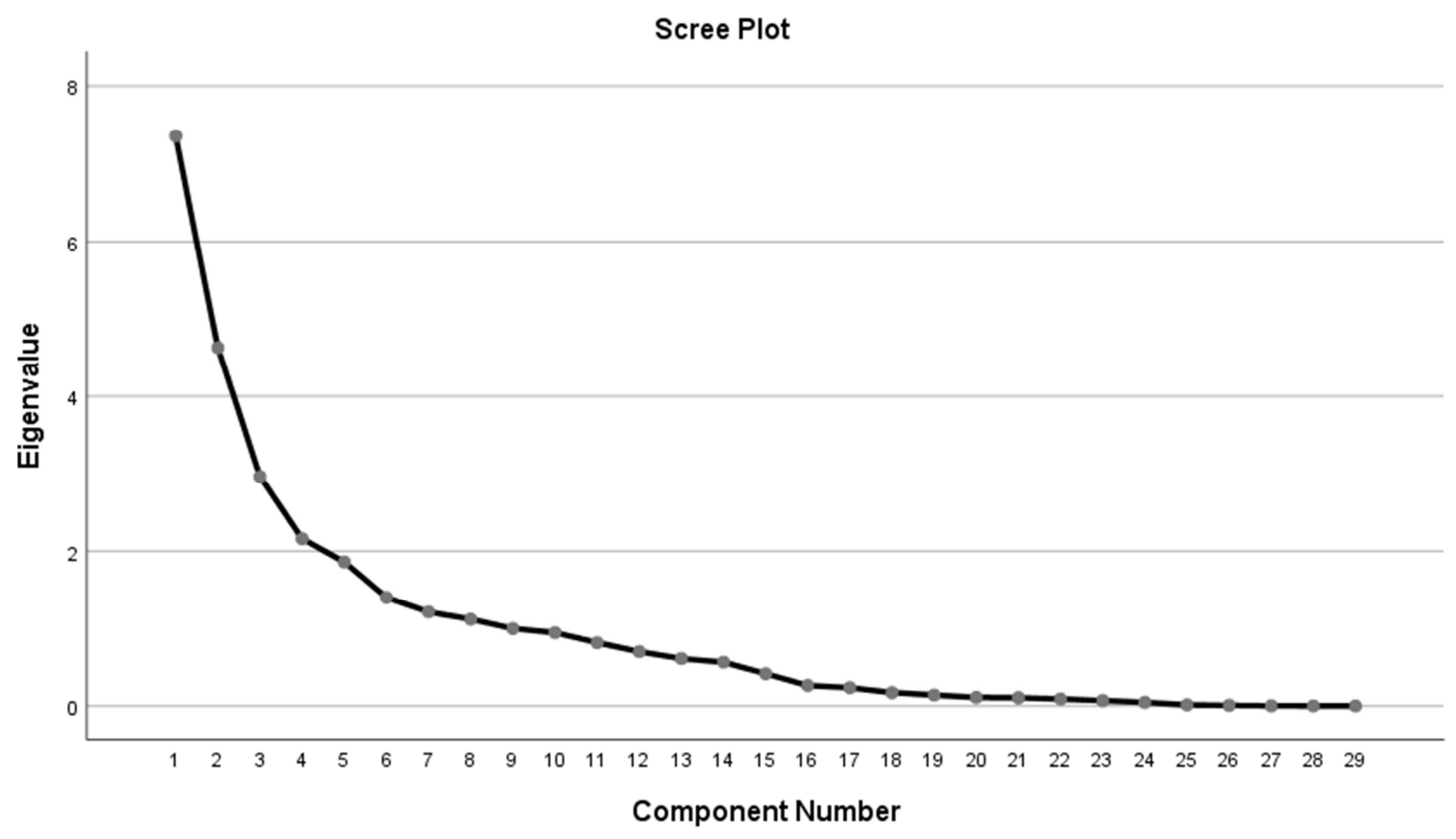

Figure 1. The Scree Plot.

Cattell's Scree test requires visual analysis of a graphical representation of eigenvalues for point of inflection. The observations above the point of inflection (including the point itself) will inform the number of factors to be retained.
Researcher's judgment is required in the decision for the number of factors to retain which introduces subjectivity. The subjectivity is reduced for larger sample size [15].

There appears to be a marked decrease in downward slope 
after the fourth principal component

implying that the preceding five principal components can be summarized as being representative of the variables in totality. This is in not in line with the Kaiser criterion (eigenvalue greater than one rule) which extracted 8 factors out of the 29 .

Table 5. Parallel Analysis.

\begin{tabular}{lll}
\hline Mean Eigenvalue from & Eigen values from dataset & $\begin{array}{l}\text { Eigenvalues } \\
\text { retained }\end{array}$ \\
\hline Parallel Analysis & (Kaisor eigen value $>$ 1 rule) & 7.353 \\
1.436368 & 7.353 & 4.629 \\
1.377602 & 4.629 & 2.963 \\
1.329983 & 2.963 & 2.159 \\
1.287357 & 2.159 & 1.859 \\
1.252328 & 1.859 & 1.400 \\
1.221142 & 1.400 & 1.211 \\
1.188662 & 1.211 & \\
1.162285 & 1.117 & \\
\hline
\end{tabular}

The Kaiser's eigenvalue $>1$ rule requires factors with eigenvalues exceeding 1 to be the only ones to be retained.
Parallel analysis (although less applied) has been pointed out by many researchers as the most robust method for retaining factors [15].

Table 5 (second column), the Kaiser's rule output suggests retaining of 8 factors. The parallel analysis was performed with parameters of 29 economic variables and 583 data points. Percentile Eigen value was set at 95 and the default to generate 100 correlation matrices was maintained. The Eigen values computed from the randomly generated correlation matrices of the parallel analysis were compared with the Eigen values extracted from the data set. The factors which had their Eigen values from the data set exceeding that from that parallel analysis were retained with those failing the threshold considered as spurious as shown in Table 5. To this end, 7 factors were retained. Whereas the Kaiser criterion extracted 8 factors, the parallel analysis suggested retaining only 7 of these out of the 29 variables. To this end, 7 factors were retained for further analysis since the parallel analysis method has been noted as the most robust compared to Scree test and Kaiser criterion (Scott, et al. 1995).

Table 6. Total Variance Explained.

\begin{tabular}{|c|c|c|c|c|c|c|c|c|c|}
\hline \multicolumn{10}{|c|}{ Total Variance Explained } \\
\hline \multirow[b]{2}{*}{ Component } & \multicolumn{3}{|c|}{ Initial Eigenvalues } & \multicolumn{3}{|c|}{ Extraction Sums of Squared Loadings } & \multicolumn{3}{|c|}{ Rotation Sums of Squared Loadings } \\
\hline & Total & $\begin{array}{l}\text { \% of } \\
\text { Variance }\end{array}$ & Cumulative\% & Total & $\%$ of Variance & $\begin{array}{l}\text { Cumulative } \\
\%\end{array}$ & Total & $\%$ of Variance & $\begin{array}{l}\text { Cumulative } \\
\%\end{array}$ \\
\hline 1 & 7.353 & 25.356 & 25.356 & 7.353 & 25.356 & 25.356 & 4.498 & 15.511 & 15.511 \\
\hline 2 & 4.629 & 15.961 & 41.317 & 4.629 & 15.961 & 41.317 & 4.253 & 14.666 & 30.177 \\
\hline 3 & 2.963 & 10.216 & 51.533 & 2.963 & 10.216 & 51.533 & 4.121 & 14.210 & 44.387 \\
\hline 4 & 2.159 & 7.445 & 58.979 & 2.159 & 7.445 & 58.979 & 3.448 & 11.890 & 56.277 \\
\hline 5 & 1.859 & 6.411 & 65.389 & 1.859 & 6.411 & 65.389 & 2.106 & 7.262 & 63.539 \\
\hline 6 & 1.400 & 4.827 & 70.216 & 1.400 & 4.827 & 70.216 & 1.875 & 6.464 & 70.003 \\
\hline 7 & 1.211 & 4.176 & 74.392 & 1.211 & 4.176 & 74.392 & 1.273 & 4.390 & 74.392 \\
\hline 8 & 1.117 & 3.852 & 78.245 & & & & & & \\
\hline 9 & .997 & 3.439 & 81.684 & & & & & & \\
\hline 10 & .943 & 3.253 & 84.937 & & & & & & \\
\hline 11 & .816 & 2.813 & 87.750 & & & & & & \\
\hline 12 & .700 & 2.412 & 90.162 & & & & & & \\
\hline 13 & .610 & 2.103 & 92.266 & & & & & & \\
\hline 14 & .563 & 1.943 & 94.208 & & & & & & \\
\hline 15 & .415 & 1.432 & 95.640 & & & & & & \\
\hline 16 & .264 & .909 & 96.549 & & & & & & \\
\hline 17 & .235 & .812 & 97.360 & & & & & & \\
\hline 18 & .172 & .595 & 97.955 & & & & & & \\
\hline 19 & .141 & .485 & 98.440 & & & & & & \\
\hline 20 & .110 & .380 & 98.820 & & & & & & \\
\hline 21 & .107 & .368 & 99.188 & & & & & & \\
\hline 22 & .090 & .311 & 99.499 & & & & & & \\
\hline 23 & .069 & .239 & 99.738 & & & & & & \\
\hline 24 & .048 & .164 & 99.902 & & & & & & \\
\hline 25 & .015 & .052 & 99.954 & & & & & & \\
\hline 26 & .008 & .028 & 99.982 & & & & & & \\
\hline 27 & .003 & .011 & 99.993 & & & & & & \\
\hline 28 & .001 & .005 & 99.998 & & & & & & \\
\hline 29 & .001 & .002 & 100.000 & & & & & & \\
\hline
\end{tabular}

Extraction Method: Principal Component Analysis.

The first component explains about $25.4 \%$ of the total variance. The second component explains about $16 \%$ of the overall variance. The third component explains about $10.2 \%$ of the total variation and so on and so forth. It can be observed that the first component recorded the greatest variance followed by the second component with the remaining components following the same decreasing trend of variance. Orthogonal Varimax technique was employed to produce uncorrelated factor structures. The summarized overall variation in the original set of variables per the 7 
retained variables was about $74.4 \%$.

Table 7. Rotated Component Matrix ${ }^{a}$

\begin{tabular}{|c|c|c|c|c|c|c|c|}
\hline \multicolumn{8}{|c|}{ Rotated Component Matrix $^{\mathrm{a}}$} \\
\hline & \multicolumn{7}{|c|}{ Component } \\
\hline & 1 & 2 & 3 & 4 & 5 & 6 & 7 \\
\hline CPIF & -.128 & .898 & -.202 & .224 & .095 & .107 & .014 \\
\hline CPINF & -.102 & .851 & -.201 & .359 & .110 & .088 & .036 \\
\hline CPIO & -.113 & .840 & -.177 & .305 & .114 & .096 & .042 \\
\hline INFF & .232 & -.219 & .805 & -.197 & -.169 & -.129 & .028 \\
\hline INFNF & .128 & -.211 & .894 & -.063 & -.005 & -.014 & -.052 \\
\hline INFYAV & .072 & -.284 & .815 & -.235 & .003 & -.012 & .024 \\
\hline INTYOY & .181 & -.234 & .909 & -.115 & -.072 & -.072 & -.015 \\
\hline M1 & .046 & .139 & -.177 & .957 & .069 & .077 & -.022 \\
\hline M2 & .046 & .150 & -.176 & .956 & .072 & .071 & -.022 \\
\hline M2PLUS & .048 & .140 & -.174 & .958 & .072 & .072 & -.021 \\
\hline MPR & .050 & -.686 & .551 & -.148 & .174 & -.011 & .059 \\
\hline TotDep & .672 & .057 & .051 & .093 & 206 & .143 & .020 \\
\hline TotCred & .041 & .061 & .024 & -.011 & .255 & .201 & -.590 \\
\hline TBR91day & -.404 & -.423 & .308 & -.012 & .037 & .307 & .205 \\
\hline TBR182DAY & -.063 & -.302 & -.491 & .108 & .425 & -.178 & -.089 \\
\hline TBRIYEAR & -.055 & -.076 & .023 & .021 & -.101 & -.146 & -.164 \\
\hline STD & -.007 & -.133 & -.137 & .202 & -.140 & .791 & -.108 \\
\hline RMPGRATE & .046 & .021 & -.044 & -.054 & -.021 & .008 & .719 \\
\hline RM & .936 & -.132 & .127 & .093 & .020 & -.091 & .035 \\
\hline QM & .884 & -.015 & .274 & -.036 & .028 & .066 & .036 \\
\hline PSCREDIT & .031 & -.174 & .353 & .069 & .188 & .184 & .504 \\
\hline PETROLEUM & -.048 & .767 & -.125 & -.196 & -.107 & -.177 & -.058 \\
\hline $\mathrm{CIC}$ & .914 & -.159 & .096 & .107 & .074 & -.132 & .035 \\
\hline BNCG & .909 & -.093 & .128 & -.121 & .064 & -.038 & .035 \\
\hline BCROIL & -.099 & .127 & .053 & .020 & .145 & .889 & .032 \\
\hline DDR28 & -.088 & -.029 & .022 & -.016 & .205 & -.140 & -.016 \\
\hline DIREq28 & .261 & .039 & -.102 & .121 & .890 & .120 & -.008 \\
\hline DIREQ56 & .300 & .096 & -.097 & .131 & .866 & .134 & -.033 \\
\hline CIAER & -.465 & -.506 & .185 & .344 & .103 & -.189 & .204 \\
\hline
\end{tabular}

Extraction Method: Principal Component Analysis.

Rotation Method: Varimax with Kaiser Normalization.

a. Rotation converged in 7 iterations.

Component 1 which is highly correlated (Table 7) with 5 original variables (Total Deposit, Reserve Money, Quasi Money, Consumption index component, and Bank of Ghana Composite Index of Economic Activity (Nominal Growth) was more resembling of a monetary economy.

Component 2 was powerfully correlated (Table 7) with 7 original variables (Consumer price index-food, consumer price index-nonfood, consumer price index overall, Monetary policy rate, crude oil, core inflation adjusted for energy and utility, and 91-dayTreasury Bill was typical of a closed economy without government activity. This is because the indicators are made of mainly investment and consumption factors.

Component 3 which is highly correlated with 5 original variables (Inflation-food, Inflation-nonfood, inflationaverage of year, Inflation-year-on-year, 182-Day Treasury
Bill) is a more representative of an inflationary economy.

Component 4 is highly correlated with three variables (Narrow Money, Broad Money and Total Liquidity) and a clear case of monetary economy.

Component 5 was highly correlated with 2 original factors (tax-equivalent on treasury bill 28 days, and tax equivalent on Treasury bill 56 days) is a representation of a closed economy with government activity. This is because the indicators are made of investment and government activity (eg. Tax on treasury).

Component 6 has two variables with high correlation (Savings \& Time deposits, and International Brent Crude Oil (US\$/Barrel) - Monthly Average).

Component 7 has three highly correlated variables (Total Credit, Reserve Money Policy Rate and Private sector credit.

Table 8. Model Summary.

\begin{tabular}{lllll}
\hline Model Summary & & & \\
\hline Model & R & R Square & Adjusted R Square & Std. Error of the Estimate \\
\hline 1 & $.551^{\mathrm{a}}$ & .304 & .289 & 1.97120 \\
\hline
\end{tabular}

a. Predictors: (Constant), REGR factor score 7 for analysis 1, REGR factor score 5 for analysis 1, REGR factor score 1 for analysis 1, REGR factor score 6 for analysis 1, REGR factor score 3 for analysis 1, REGR factor score 2 for analysis 1, REGR factor score 4 for analysis 1. 
Table 9. ANOVA

\begin{tabular}{lllllll}
\hline ANOVA $^{\mathbf{a}}$ & & & & & \\
\hline Model & & Sum of Squares & df & Mean Square & F & Sig. \\
\hline \multirow{3}{*}{1} & Regression & 563.394 & 7 & 80.485 & 20.714 & $.000^{\mathrm{b}}$ \\
& Residual & 1290.026 & 332 & 3.886 & & \\
& Total & 1853.420 & 339 & & & \\
\hline
\end{tabular}

a. Dependent Variable: GDP.

b. Predictors: (Constant), REGR factor score 7 for analysis 1, REGR factor score 5 for analysis 1, REGR factor score 1 for analysis 1 , REGR factor score 6 for analysis 1, REGR factor score 3 for analysis 1, REGR factor score 2 for analysis 1, REGR factor score 4 for analysis 1.

There was a statistically significant difference among the 7 components.

Table 10. Coefficients.

\begin{tabular}{|c|c|c|c|c|c|c|}
\hline \multicolumn{7}{|c|}{ Coefficients $^{\mathrm{a}}$} \\
\hline \multirow{2}{*}{ Model } & & \multicolumn{2}{|c|}{ Unstandardized Coefficients } & \multirow{2}{*}{$\begin{array}{l}\text { Standardized Coefficients } \\
\text { Beta }\end{array}$} & \multirow{2}{*}{$\mathbf{t}$} & \multirow{2}{*}{ Sig. } \\
\hline & & B & Std. Error & & & \\
\hline \multirow{8}{*}{1} & (Constant) & 4.564 & .239 & & 19.085 & .000 \\
\hline & REGR factor score 1 for analysis 1 & -.051 & .091 & -.028 & -.556 & .579 \\
\hline & REGR factor score 2 for analysis 1 & .600 & .135 & .224 & 4.436 & .000 \\
\hline & REGR factor score 3 for analysis 1 & -.021 & .120 & -.011 & -.177 & .860 \\
\hline & REGR factor score 4 for analysis 1 & -3.927 & .571 & -.468 & -6.882 & .000 \\
\hline & REGR factor score 5 for analysis 1 & .386 & .104 & .193 & 3.720 & .000 \\
\hline & REGR factor score 6 for analysis 1 & -.577 & .114 & -.260 & -5.063 & .000 \\
\hline & REGR factor score 7 for analysis 1 & -.256 & .104 & -.116 & -2.475 & .014 \\
\hline
\end{tabular}

a. Dependent Variable: GDP.

The components 2 (closed economy without government activity) and 5 (a closed economy with government activity) were significant and positively related with GDP. However, components 4 (monetary economy), component 6 , and 7 are negatively related with GDP and statistically significant. Components 1 (monetary economy) and 3 (inflationary economy) however were not statistically significant and had negative impact on GDP.

\section{Conclusion}

The paper aimed at modeling the relationship between GDP and 29 macroeconomic variables in Ghana using the PCA and multiple linear regressions methods. Economic data with 583 data points were collected from January, 1990 through to May, 2018. Seven factors were retained (explained $74 \%$ of the overall variation) after using multiple extraction approaches of scree test, Kaiser Criterion, and parallel analysis to avoid over- and under-extraction. Regression analysis was performed where component scores were used to develop a relationship with the uncorrelated components and GDP. Closed Economy without Government Activities explicitly contained seven indicators consisting of consumer price index-Food, Consumer price index-Nonfood, Consumer Price index overall, Monetary Policy Rate, 91-DaysTreasury, 182-Days Treasury Bill, crude oil, and Core Inflation (Adjusted for Energy \& Utility was significant and positively related with GDP $(\mathrm{B}=0.6, \mathrm{p}<0.01)$. Closed Economy with Government activities explicitly contained two indicators such as TaxEquivalent Rate on the 28-DayTreasury Bill and TaxEquivalent Rate on 56-Day Treasury Bill had a significant impact on GDP $(\mathrm{B}=0.386, \mathrm{p}<0.01)$.

\section{Recommendation}

Future researchers should consider increasing the number of macroeconomic variables to increase the predictive power of the model.

\section{References}

[1] Armeanu D, Lache L. (2018): Application of the Model of Principal Components Analysis on Romanian Insurance Market, Theoretical and Applied Economics.

[2] Fan J, Sun Q, Wen-Xin Z, and Ziwei Z. (2018): Principal component analysis for big data arXiv: $1801.01602 \mathrm{v} 1$ [stat. $\mathrm{ME}]$.

[3] Syeda F, Muhammad S. and Shah G. A. A (2013). Effects of Macroeconomic Variables on Gross Domestic Product (GDP) in Pakistan. International Conference on Applied Economics (ICOAE) 2013. Procedia Economics and Finance 5 (2013) 703-711.

[4] Hussain A, Hazoor M. Sabir and Kashif M (2016). Impact of macroeconomic variables on GDP: evidence from Pakistan European Journal of Business and Innovation Research Vol. 4, No. 3, pp. 38-52, June 2016.

[5] Purnamasari D. U, Surawidarto M., Dedek Hadi A. S, and Istiyono E., (2019), "Exploratory Factor Analysis: Motivation for Learning" in The FirstInternational Conferenceon Education, Science and Training: Empowering Educational Human Resources for Global Competitiveness, KnE Social Sciences, pages58-65. DOI10.18502/kss.v3i15.4354. 
[6] Adongo F. A, John Amo Jr. L, Chikelu C. J, Osei M, (2018): Principal Component and Factor Analysis of Macroeconomic Indicators, IOSR Journal Of Humanities And Social Science (IOSR-JHSS) Volume 23, Issue 7, Ver. 10 (July. 2018) PP 0107 e-ISSN: 2279-0837, p-ISSN: 2279-0845. www.iosrjournals.org.

[7] Razzak H, Ali M, (2015): Principal Component Analysis Of Socioeconomic Factors And Their Association With Life Expectancy At Birth In Asia, International Journal of Multidisciplinary Academic Research Vol. 3, No. 1, 2015, ISSN 2309-3218.

[8] Twenefour F. B. K., Nortey E. N. N., Baah, E. M. (2015): Principal Component Analysis of Students Academic Performance International Journal of Business and Social Research, Volume 05, Issue 02, 2015.

[9] Field, A. P. (2005). Discovering statistics using SPSS (2nd edition). London: Sage.

[10] Scott F. B., Gibson, David J., Robertson, Philip A., Pohlmann,
John T. and Fralish, James S. (1995): "Parallel Analysis: a Method for Determining Significant Principal Components." (Feb 1995).

[11] Williams B. (2012): Exploratory factor analysis: A five-step guide for novices. Australasian Journal of Paramedicine Volume 8 | Issue 3.

[12] Hans P. F \& Janssens E. (2019). Spurious principal components, Applied Economics Letters, 26: 1, 37-39, DOI: $10.1080 / 13504851.2018 .1433292$.

[13] Schwarz J. (2011): Research Methodology: Tools, Applied Data Analysis (with SPSS), Lecture 03: Factor Analysis.

[14] Mehmedinovic S. (2017) Fundamentals Of Application Factor Analysis In Education And Rehabilitation, DOI: 10.21554/hrr.041708.

[15] Taherdoost H., Sahibuddin S., Jalaliyoon N. (2010) Exploratory Factor Analysis; Concepts and Theory, Advances in Applied and Pure Mathematics ISBN: 978-960-474-380-3. 